\title{
Why Do Participants Draw Non-Valid Inferences in Conditional Reasoning?
}

N. Verschueren, W. Schroyens, W. Schaeken and G. D'Ydewalle

\section{(2) OpenEdition}

Electronic version

URL: http://journals.openedition.org/cpl/199

DOI: $10.4000 / \mathrm{cpl} .199$

ISSN: $1379-6100$

Publisher

Centre PsyCLÉ

Printed version

Date of publication: 1 December 2001

\section{Electronic reference}

N. Verschueren, W. Schroyens, W. Schaeken and G. D'Ydewalle, « Why Do Participants Draw Non-Valid Inferences in Conditional Reasoning? », Current psychology letters [Online], 2001/3, 6 | 2001, Online since 05 September 2003, connection on 08 September 2020. URL : http://journals.openedition.org/ cpl/199; DOI : https://doi.org/10.4000/cpl.199

This text was automatically generated on 8 September 2020

(C) All rights reserved 


\section{Why Do Participants Draw Non- Valid Inferences in Conditional Reasoning?}

N. Verschueren, W. Schroyens, W. Schaeken and G. D'Ydewalle 